\title{
Animal Models of Fibromyalgia
}

\author{
Yukinori Nagakura, Hiroyuki Ito and Yasuaki Shimizu \\ Drug Discovery Research, Astellas Pharma Inc., \\ Japan
}

\section{Introduction}

Fibromyalgia patients are suffering distressing pain-centered symptoms, and therefore the clarification of fibromyalgia pathophysiology and the development of more effective therapeutic options are urgent issues. In the preclinical phase of analgesic drug development, experimental animal pain models have been widely used to investigate analgesic efficacies of candidate agents. In this approach, some kind of manipulations are conducted to induce clinically relevant pain states such as hyperalgesia and allodynia in the experimental animal, and then, pain-associated behaviors are measured as indicators of pain. Efficacy of test drugs on the said pain is finally evaluated. While animal pain models associated with neuropathy or inflammation have been well established and used in drug discovery research (Negus et al., 2006), only a few have been developed for examining fibromyalgia. This chapter focuses on the review of putative animal models of fibromyalgia, which mimic some features of patients with fibromyalgia.

\section{Challenges accompanying the development of fibromyalgia animal model}

Widespread chronic pain is a core symptom in fibromyalgia patients, and manifestation of this pain is a necessary and extremely important criterion in developing fibromyalgia animal models. Chronic pain can be categorized into three groups according to the mechanism underlying the pain: nociceptive pain, which is caused by tissue damage including inflammation; neuropathic pain, which is caused by a dysfunction in nerve fibers; and central (non-nociceptive) pain, where the central disturbance in pain processing is involved (Clauw, 2009). Animal models for nociceptive and neuropathic pain are well established and have significantly contributed to the development of therapeutic options since relatively early times (Negus et al., 2006), due in part to the relatively easy-to-mimic etiology of nociceptive and neuropathic pain. For example, controlled damage to the sensory nerve fibers by surgical, infectious, or chemical manipulation can effectively induce neuropathic pain, while damaging the tissues by surgical or inflammatory means can effectively induce nociceptive pain. On the other hand, the development of the animal model of central (non-nociceptive) pain is rather difficult due to the unknown etiology. Namely, it is challenging to specify the relevant trigger of experimental pain due to the poor understanding of the nociceptive source. Consequently, animal models for fibromyalgia, a disease that exhibits typical central (non-nociceptive) pain, are relatively naive.

Also complicating such models is the fact that fibromyalgia is not a simple pain state but rather is accompanied by multiple comorbid symptoms including depression, fatigue, sleep 
disturbance, irritable bowel syndrome, and irritable bladder syndrome (Clauw, 2009), and patients often experience one or more of these comorbidities in addition to widespread pain. One report plotted the prevalence of fatigue, sleep disturbance, and depression in fibromyalgia patients at approximately $80 \%, 90 \%$, and $40 \%$, respectively, although the prevalence varies across the population (Sluka, 2009). In 2010, new diagnostic criteria for fibromyalgia were proposed by the American College of Rheumatology (Wolfe et al., 2010). The criteria include widespread pain index, but no longer require tender point examination. Alternatively, they include severity scores of comorbid symptoms such as cognitive symptoms, unrefreshed sleep, and fatigue. Given this correlation between comorbidities and pain in fibromyalgia patients, corresponding animal models should ideally simulate the development of these symptoms in addition to chronic pain; concurrent consideration for depression, fatigue, and visceral organ function is important when investigating the chronic pain state in fibromyalgia animal models.

Given that fibromyalgia predominantly occurs in women, it would be worth to consider the involvement of female animals in the construction of fibromyalgia animal model. However, because estrous cycle influences nociceptive processing in both peripheral and central pathways (Fillingim and Ness, 2000), this cycle could be a confounding bias in the preclinical pain research. Thus, it would be necessary to assess carefully the estrous cycle phase when using female animals in preclinical experiment.

\section{Hypotheses for fibromyalgia pathogenesis}

Several hypotheses have been proposed regarding fibromyalgia pathogenesis and should be considered when designing a suitable animal model.

Fibromyalgia is generally considered to be a stress-related disorder. Stress plays an exacerbating role in the development of somatic symptoms including chronic pain. There is evidence that disparate stressful events including childhood abuse and physical traumas would trigger the development of fibromyalgia (Clauw, 2009).

Alternatively, an abnormal neuroendocrine system may be involved in the pathogenesis, as stress affects the hypothalamic-pituitary-adrenal axis and the autonomic nervous system. Indeed, altered function of the hypothalamic-pituitary-adrenal axis has been detected in at least some subpopulation of fibromyalgia patients, and aberrations in the autonomic nervous system are also often observed (Bradley, 2009).

Many fibromyalgia patients experience pain in deep tissues such as muscle. Abnormalities in the local muscle tissue may therefore underlie the pathogenesis, as changes of intramuscular microcirculation or muscle energy metabolism have been detected in the musculoskeletal tissue of some fibromyalgia patients. This localized muscle pain may eventually spread throughout the body via a central nervous system-mediated mechanism, thereby leading to nociceptive input from the deep tissue and generating central sensitization in the spinal cord and brain. After this central sensitization is established, a chronic pain state can be maintained by even minimal nociceptive input from the peripheral tissues (Nielsen \& Henriksson, 2007). The pain assessment by using spinal nociceptive flexion reflex (NFR), a correlate for the evaluation of central nociceptive pathways, suggests that abnormally processed nociceptive signal input to central nociceptive pathways (i.e., central sensitization) underlies the pathophysiology in fibromyalgia patients (Desmeules et al., 2003). Also, attenuation of inhibitory pain control in the central nervous system seems to be involved in development of fibromyalgia. Ascending nociceptive input to the supraspinal 
brain is down-regulated by the brainstem descending pain inhibitory pathway, where neurotransmitters associated with the regulation of both pain and mood operate. Dysfunction in this inhibitory pain control has been suggested to play an important role in the pathogenesis of fibromyalgia. Indeed, diffuse noxious inhibitory control (DNIC), an indicator for activity in the central descending pain inhibitory pathway, has been found to be attenuated in many fibromyalgia patients (Clauw, 2009).

\section{Approach for developing fibromyalgia animal models}

Given the different etiology between fibromyalgia (central pain) and nociceptive/neuropathic pain, animal models more specific to fibromyalgia need to be developed. In this chapter, we discuss several noteworthy animal models that mimic certain major fibromyalgia features based on three types of validation: construct validity ("Is induction of the disease state in accordance with the fibromyalgia etiology?" Animal models should be constructed based on the aforementioned hypotheses), face validity ("Do fibromyalgia-like symptoms successfully manifest?" Animal models should exhibit chronic pain symptoms and accompanying comorbidities), and predictive validity ("How do the symptoms respond to treatments used in the clinical setting?" Although some drugs have been approved for the treatment of fibromyalgia-associated pain, the effect size of these drugs seems not sufficient).

\section{Key animal models}

The animal models to be reviewed in this chapter are the repeated cold stress model, the unpredictable sound stress model, the intramuscular acidic saline injection model, and the reserpine-induced myalgia model, in which assumed causes of chronic pain are unavoidable stress, stress-induced disruption of the neuroendocrine system, an initial local muscle abnormality that spreads throughout the body, and dysfunctional pain control in the central nervous system, respectively. All four models operate on the common premise that once chronic pain is established, no apparent organic disorder can explain its persistence. Further, the pain symptoms are not localized to the ipsilateral side, instead spreading to the contralateral side of the body as well.

\subsection{Repeated cold stress model}

\subsubsection{Methods}

The repeated cold stress model was first introduced as an animal model to study autonomic imbalance in response to sudden changes in environmental temperature (Kita et al., 1975; Ohara et al., 1991). Mice exposed to repeated cold stress develop several abnormal physiologies such as a continuous lowering of blood pressure, sympathicotonic-type electrocardiogram (ECG), depression-like behaviors, and hyperalgesia (Ohara et al., 1991). In this model, animals (usually mice) are kept in a room at a temperature alternating between 24 and $4^{\circ} \mathrm{C}$ every hour in the day time, and then kept at $4^{\circ} \mathrm{C}$ overnight. This procedure was repeated for 5 days or more (Kita et al., 1975; Hata et al., 1995).

Nishiyori and Ueda (2008) revisited this stress model to demonstrate its utility as a putative animal model for fibromyalgia. They optimized the repeated cold stress protocol to induce long lasting mechanical and thermal hyperalgesia in mice as follows. On Day 1, the 
experiment starts with exposing mice to a cold temperature $\left(4^{\circ} \mathrm{C}\right)$ overnight until morning the next day. From there, the temperature is then alternated between 24 and $4^{\circ} \mathrm{C}$ every 30 min in the day time. This is repeated until morning on Day 4. A nociception test is then conducted at room temperature at least $1 \mathrm{~h}$ after the end of stress exposure.

\subsubsection{Primary features}

Nishiyori and Ueda (2008) found that mice exhibited thermal hyperalgesia (reduction in paw withdrawal latency in response to thermal stimulation) and mechanical hyperalgesia (reduction in threshold for paw withdrawal in response to mechanical stimulation by the von Frey apparatus) for more than 12 days following the repeated cold stress. In contrast, mice exposed to constant cold temperature $\left(4^{\circ} \mathrm{C}\right)$ stress manifest only short-lasting hyperalgesia. Similarly, the repeated cold stress with the protocol by Ohara et al. (1991) caused mechanical hyperalgesia, which was maintained for 1 week after the start of stress loading, in the tail pressure test in mice.

\subsubsection{Constructive validity}

Stressors such as physical trauma, catastrophic events, hormonal alterations, and emotional stress play an important role in triggering development of fibromyalgia. Individuals exposed to these stressors have been found to develop chronic widespread pain with a relatively high probability, as indicated by studies investigating the effects of childhood abuse and posttraumatic stress disorder. Similarly, studies using animals have suggested that stressors that can neither be avoided nor controlled are more likely to cause unstable physiological responses and may lead to irreversible health problems (Clauw, 2009). This means that disparate stressors are potential factors in triggering development of fibromyalgia.

Stressors may affect physiological function by altering the hypothalamic-pituitary-adrenal axis and causing a malfunction in autonomic control. Dysfunctional autonomic control may then, in turn, associate with fibromyalgia pathogenesis. For example, the abnormality in heart rate variability, which suggests an autonomic dysfunction, is raised as a risk factor of fibromyalgia (Clauw, 2009).

Based on the suggested involvement of stressors and the dysfunction of neuroendocrine system in the pathogenesis of fibromyalgia, the sudden and frequent change in environmental temperature, which has been known to cause autonomic imbalance and hyperalgesia (Hata et al., 1988), is utilized to cause a long-lasting mechanical and thermal hyperalgesia in animals in the repeated cold stress model. Interestingly, it is not simply constant cold stress but rather repeated cycling of cold stress that causes long-lasting hyperalgesia. This may mean that animals are capable of adapting to cold environmental temperature exposure over a long period, but a sudden and frequent environmental temperature change such as that experienced in the repeated cold stress greatly affects physiological function, including autonomic control. This dysfunction in autonomic control and subsequent development of chronic pain state may be due to changes in certain neurotransmitters, as the repeated cold test has been found to also decrease serotonin and increase noradrenaline and dopamine in the central nervous system (Hata et al., 1987; Hata et al., 1991). The turnover of serotonin in the spinal cord is accordingly reluctant to be activated in mice following exposure to repeated cold stress (Nishiyori et al., 2010). 


\subsubsection{Face validity}

The repeated cold stress test performed by Nishiyori and Ueda (2008) caused long-lasting (12 days or more) mechanical and thermal hyperalgesia in the paws of both male and female mice, suggesting no apparent difference in susceptibility to repeated cold stress between genders. Intriguingly, gonadectomized male mice showed partial reversal of the repeated cold stress-induced mechanical hyperalgesia, whereas gonadectomized females did not. This difference may be related to the predominance of chronic pain occurrence in female, which is a feature of fibromyalgia epidemiology (Clauw, 2009).

In addition to hyperalgesia, the repeated cold stress causes abnormal behaviors in mice, a feature that may be associated with the comorbid symptoms seen in fibromyalgia patients. Mice loaded with repeated cold stress show a shortened immobility time in the forced swim test, a test used to assess the anti-depressive effect of drugs. Although prolonged immobility time is typically associated with depressed condition, the authors suggest that the reduced immobility time may also indicate complex symptoms such as excessive emotion- or anxiety-related depression, as immobility time recovered when the mice were given repeated injections of antidepressants or a single injection of anxiolytics (Hata et al., 1995).

\subsubsection{Predictive validity}

Gabapentin is structurally related to pregabalin, which has been approved for treatment of fibromyalgia in the USA. It is a ligand for the $\alpha 2 \delta 1$ subunit in voltage-dependent calcium channels as is pregabalin. Gabapentin was approved for the treatment of neuropathic pain such as post herpetic neuralgia, and was statistically more effective than placebo in reducing pain scores in a 12-week randomized controlled trial in fibromyalgia patients (Arnold et al., 2007). Regarding the effect size in this trial, reduction of $>$ or $=30 \%$ in average pain severity score (range $0-10$, where $0=$ no pain and $10=$ pain as bad as you can imagine) was $51 \%$ for gabapentin and $31 \%$ for placebo.

In the repeated cold stress model, gabapentin completely recovered both mechanical and thermal hyperalgesia. This efficacy of gabapentin is basically consistent with the study showing that pregabalin significantly attenuates the pain score in phase III clinical trials for fibromyalgia patients (Mease et al., 2008). In mice, the effective dose for relieving hyperalgesia in the repeated cold stress model was over three times smaller than that for reducing nerve injury-induced neuropathic pain, despite the effective dose of pregabalin being similar between fibromyalgia and neuropathic pain patients in a clinical setting (Dworkin et al., 2007; Mease et al., 2008). Further, intracerebroventricular administration of gabapentin significantly attenuated hyperalgesia in the repeated cold stress model but not in the neuropathic pain model, possibly because up-regulation of the a2 $\delta 1$ subunit may underlie the mechanism for repeated cold stress-induced hyperalgesia (Nishiyori and Ueda, 2008).

No clear evidence has yet been presented that opiate drugs are effective in reducing pain in fibromyalgia patients, as no randomized controlled double blind clinical trial on opiates has been conducted with a sufficient number of fibromyalgia patients (Clauw, 2009). One study using a small number of fibromyalgia patients did not detect any significant benefit when intravenously injecting morphine (Sörensen et al., 1995). In accordance with these findings, neither subcutaneous nor intracerebroventricular injection of morphine has been found to attenuate thermal hyperalgesia in repeated cold stressed mice. Given that serotonin turnover is unlikely to be accelerated by morphine in these animals, a dysfunction in the serotonin-mediated descending inhibitory pathway might explain the absence of morphine analgesia (Nishiyori et al., 2010). 
Neurotropin is an extracted substance from the inflamed skin of rabbits inoculated with vaccinia virus. It has been used in the treatment of chronic pain including post-herpetic neuralgia in Japan. The analgesic mechanism of neurotropin has not been fully clarified. However, the enhancement of descending pain inhibitory pathway could be involved in the mechanism and the intraperitoneal injection of neurotropin significantly attenuates the mechanical hyperalgesia in the repeated cold stressed mice (Ohara et al., 1991). There has been no study with a sufficient number of fibromyalgia patients so far, which suggests that neurotropin has beneficial effect in the treatment of fibromyalgia.

\subsection{Unpredictable sound stress model \\ 5.2.1 Methods}

In this model, animals (usually male rats) are placed in a sound box for $30 \mathrm{~min}$, during which they are randomly exposed every minute to unpredictable sounds ranging in amplitude from 20 to $105 \mathrm{~dB}$ and several frequencies for 5 or $10 \mathrm{sec}$ each. Following the test, the animals are returned to their home cage. The sound stress protocol is conducted on Days 1,3 , and 4 . Nociceptive and other behavioral experiments are conducted typically 1 or 14 days after the last sound stress delivery (Green et al., 2011; Khasar et al., 2005).

\subsubsection{Primary features}

Sound-stressed rats exhibit an aggravation of algesic substances (bradykinin or prostaglandin $\mathrm{E}_{2}$ )-induced mechanical hyperalgesia in the paw and muscle pressure tests, although they do not manifest hyperalgesia without the application of an algesic substance. These animals also manifest visceral hypersensitivity based on colorectal distension 14 days after the end of stress, even without application of exogenous algesic substances. Anxiety score as measured by the elevated plus maze test is also increased 14 days after the last stress exposure (Green et al., 2011; Khasar et al., 2005).

\subsubsection{Constructive validity}

Stress has been shown to be a risk factor for fibromyalgia development, as traumatic events are likely to trigger chronic pain symptoms (Clauw, 2009). Dysfunction in sound stressor processing has been shown to occur in some fibromyalgia patients (Dohrenbusch et al., 1997), and stressors in general have been known to affect physiological functions such as nociception by changing the sympathoadrenal (adrenaline) and hypothalamic-pituitaryadrenal (corticosterone) axes in the neuroendocrine system. Because unpredictable sound stress affects both axes and causes a prolonged elevation of plasma adrenaline levels, the stress-induced release of adrenaline (the product of neuroendocrine system activation) likely plays an important role in developing mechanical hyperalgesia in the unpredictable sound stress model. This working hypothesis is consistent with evidence of elevated plasma adrenaline levels and enhanced bradykinin-induced mechanical hyperalgesia in vagotomized rats (Khasar et al., 1998; Khasar et al., 2003; Levine and Reichling, 2005).

Hypersensitivity in the presence of pronociceptive substances is commonly observed in fibromyalgia patients (Wang et al., 2008), and the requirement of pronociceptive substances for sound-stressed animals to exhibit enhanced somatosensory function may reflect a similar feature. However, the lack of change in the baseline nociceptive threshold in the unpredictable sound stress model is inconsistent with changes noted with other types of stressors such as repeated cold stress (Nishiyori and Ueda, 2008) and repeated swim stress 
(Quintero et al., 2000). This difference may be because of the type of stressor or because of the method for measuring nociceptive function. Additionally, visceral hypersensitivity manifests even without the addition of pronociceptive substances, possibly due to the presence of endogenous pronociceptive substances in the gastrointestinal tissues, as these make sound stress-induced hyperalgesia be elicited (Green et al., 2011).

\subsubsection{Face validity}

In humans, chronic pain symptoms tend to develop on a delay after a traumatic event (RoyByrne et al., 2004). In line with this observation, sound-stressed rats develop an enhanced nociceptive response to pronociceptive substances such as bradykinin and prostaglandin E2 in the skin and muscle region not on Day 1 but on Day 14 after the end of stress exposure. Although fibromyalgia patients show somatic hypersensitivities to mechanical stimuli without exogenous application of pronociceptive substances, unpredictable sound stress does not cause significant changes in somatic sensitivity to mechanical stimuli unless pronociceptive substances are applied. Instead, plasma cytokine levels associating with the hypersensitivity seen in fibromyalgia patients (Wang et al., 2008) correlate with repeated sound stress exacerbating the pronociceptive substance-induced nociceptive response. Further, visceral hypersensitivity manifests even without the addition of exogenous pronociceptive substances (Green et al., 2011).

Similar to fibromyalgia patients who show comorbid symptoms such as irritable bowel syndrome, temporomandibular disorder, and anxiety (Clauw, 2009), sound-stressed rats manifest typical comorbid symptoms such as visceral hyperalgesia, temporomandibular hyperalgesia and an elevation of anxiety score on Day 14 after the end of stress exposure (Green et al., 2011). Abnormalities in the hypothalamic-pituitary-adrenal axis and sympathetic nervous system have also been suggested to occur in at least a subpopulation of fibromyalgia patients (Clauw, 2009), and indeed, sound-stressed rats manifest a long-lasting elevation of plasma adrenaline concentration (Khasar et al., 2005).

\subsubsection{Predictive validity}

Little information is available regarding the pharmacotherapeutic efficacy on nociceptive responses induced by sound stress-induced exacerbation so far. However, because adrenal medullectomy but not sympathectomy inhibits this exacerbation, adrenaline derived from the adrenal medulla appears to play a primary role in the exacerbation mechanism in this model (Khasar et al., 2005). Pharmacotherapy for correcting the neuroendocrine abnormality may improve the enhanced sensitivity.

\subsection{Intramuscular acidic saline injection model \\ 5.3.1 Methods}

Rats are typically used in this model. Each animal receives two repeated $100-\mu l$ injections of acidic saline (adjusted to $\mathrm{pH} 4.0$ ) in the same unilateral gastrocnemius muscle under inhaled anesthesia, a procedure which is repeated five days later (Sluka et al., 2001).

\subsubsection{Primary features}

After the second injection of acidic saline, the animal manifests bilateral cutaneous and muscle mechanical hyperalgesia, which is detected as a reduction in the paw withdrawal threshold based on the von Frey filament test and the muscle pressure test in the 
gastrocnemius muscle. These hyperalgesia symptoms are long-lasting (two weeks or more). However, the animal does not exhibit thermal hyperalgesia, which is measured based on paw withdrawal latency in the radiant heat exposure test. The rat displays no motor impairment, as assessed by the treadmill test, nor any histopathological change specific to the acidic acid saline injection in the affected gastrocnemius muscle (Sluka et al., 2001; Yokoyama et al., 2007).

\subsubsection{Constructive validity}

In humans, local acidity in the muscle or skin has several causes, including inflammation and ischemia, and can induce pain initially at a local region. A previous study found that muscle pain is caused by an infusion of acid phosphate buffer into the forearm muscle (Issberner et al., 1996). Another study (Graven-Nielsen et al., 1997) showed that repeated infusion of hypertonic saline caused the pain to diffuse from the primary infusion site (tibialis anterior muscle) to other regions like the ankle. The intensity of the diffused pain becomes larger in the short interval of infusion than in the long interval. Taken together, these previous findings suggest that repeated infusions of saline into the muscle can cause pain to spread beyond the original local region. This spreading may be analogous to the widespread musculoskeletal pain that is a main feature in fibromyalgia. Based on the working hypothesis that the spread of initially localized pain underlies the process of fibromyalgia development, the acidic acid injection was used as the trigger of wide spreading pain in the intramuscular acidic saline injection model. In consistent with the clinical features, not single but repeated injections successfully induced the chronic mechanical hyperalgesia in cutaneous and muscle tissues outside the area of injection, both ipsilaterally and contralaterally.

Regarding the mechanism of this spreading in fibromyalgia patients, several studies have suggested involvement of enhanced synaptic activity in the central nervous system, including the spinal cord, and an attenuation of descending inhibitory control from supraspinal centers (Graven-Nielsen and Arendt-Nielsen, 2010). Actually, the nociceptive flexion reflex (NFR), a psychophysiological tool to study spinal nociceptive process (France et al., 2009), suggests that central sensitization is involved in fibromyalgia pain as a key mechanism (Desmeules et al., 2003). Since an injection of lidocaine into the ipsilateral gastrocnemius muscle did not affect the spreading of pain, it is unlikely that the continuous nociceptive signal input from the primary afferent neurons is mainly implicated in the spreading of pain in the intramuscular acidic saline injection model. Alternatively, the development of contralateral hyperalgesia implies the involvement of central mechanism. Actually, intrathecal administration of glutamate receptor antagonists after the second acidic acid saline injection inhibits the spreading of pain (Skyba et al., 2002), and the injection of a local anesthetic or a $N$-methyl- $D$-aspartate (NMDA) receptor antagonist into the rostral ventromedial medulla, which plays a critical role in the descending pain control, also prevents the development of the bilateral hyperalgesia (Tillu et al., 2008; Da Silva et al., 2010). Further, activation of mu- and delta-opioid receptors in the spinal cord attenuates the hyperalgesia (Sluka et al., 2002). These evidences suggest that the sensitization mainly in the spinal cord level rather than the peripheral level and the modulation of descending pain control pathway underlie the pathophysiology in this model in accordance with existing theories for the pathophysiology in fibromyalgia patients (Clauw, 2009). 


\subsubsection{Face validity}

The nociceptive source of fibromyalgia pain has yet to be identified. In general, no apparent inflammation or tissue injury can explain the pain endured by fibromyalgia patients. In line with this, no specific pathological changes specific to acidic saline injection have been detected (Sluka et al., 2001), meaning no organic disorder has been identified that can explain the widespread pain.

Intramuscular acidic saline injection model rats develop long-lasting bilateral muscle hyperalgesia (Yokoyama et al., 2007) in accordance with the deep tissue hyperalgesia and existence of tender points around the body seen in fibromyalgia patients. These animals also exhibit chronic cutaneous tactile allodynia, also consistent with findings in fibromyalgia patients. However, these animals do not develop thermal hyperalgesia (Sluka et al., 2001). Instead, visceral hyperalgesia detected by electromyography occurs concurrently with somatic hyperalgesia, suggesting that somatic afferent input from the gastrocnemius muscle induces visceral hyperalgesia, possibly via viscerosomatic convergence at the level of the lower spinal cord (Miranda et al., 2004). This finding is consistent with those in fibromyalgia patients who frequently show abdominal hypersensitivity, such as irritable bowel syndrome.

\subsubsection{Predictive validity}

A phase III clinical trial with fibromyalgia patients showed that pregabalin is efficacious and safe for use in treating pain associated with fibromyalgia, although it frequently causes dizziness and somnolence (Mease et al., 2008). A recent systematic review of the effectiveness of antiepileptic drugs for fibromyalgia suggests that pregabalin is modestly effective, although long-term safety and efficacy results are unavailable (Siler et al., 2011). In intramuscular acidic saline injection model, pregabalin significantly recovers the lowered mechanical thresholds at a dose range of $10-100 \mathrm{mg} / \mathrm{kg}$ i.p. but significantly reduces motor function outcome, as determined by the rota-rod performance test, at $30 \mathrm{mg} / \mathrm{kg}$ i.p. or more (Yokoyama et al., 2007). This result may reflect the clinically narrow margin between analgesic and dizzying doses.

\subsection{Reserpine-induced myalgia (RIM) model}

\subsubsection{Methods}

Rats are usually used. They are housed individually in the cage and are subcutaneously administered reserpine at $1 \mathrm{mg} / \mathrm{kg}$ once daily for three consecutive days. Hyperalgesia is typically evaluated on Day 5 after the last reserpine injection (Nagakura et al., 2009). Because tenderness to palpation is a diagnostic criterion for fibromyalgia and blunt pressure loading is frequently used to estimate muscular pain thresholds in humans, the muscle pressure test is used (Petzke et al., 2003).

\subsubsection{Primary features}

In male and female rats, repeated administration of reserpine significantly reduced the muscle pressure threshold based on muscle pressure test results and tactile allodynia based on the von Frey hair test results, lasting for more than one week. This administration decreased the amount of biogenic amines (dopamine, norepinephrine, and serotonin) in the spinal cord, thalamus, and prefrontal cortex, all of which are responsible for pain signal processing in the central nervous system. Further, reserpine significantly increased the 
immobility time in the forced swim test, which is indicative of depression, a common comorbid symptom in fibromyalgia patients. However, the general condition of the animals did not deteriorate, as both tremor and hypokinesia symptoms disappeared by Day 3 or later after the last reserpine injection. Additionally, no significant difference was noted in either blood pressure or rectal temperature between reserpine- and vehicle-treated groups. Taken together, these findings suggest that reserpine produces chronic pain symptoms and depressive conditions by influencing pathways that regulate nociception and depression (Nagakura et al., 2009).

\subsubsection{Constructive validity}

Functional magnetic resonance imaging studies have shown augmented central pain processing in fibromyalgia patients. This augmented processing can be thought of as a central nervous system that is hyper-reactive to a wide range of stimuli (Clauw, 2009). While several transmitters have been known to play a role in excitatory and inhibitory pain control in the central nervous system, biogenic amines like dopamine, norepinephrine, and serotonin are particularly important for analgesic control in the descending inhibitory pathway in the brainstem (Mense, 2000; Wood, 2008). Therefore, it is plausible that a dysfunction in biogenic amine-mediated inhibitory pain control underlies the central augmentation and pain-centered complex symptoms seen in fibromyalgia patients.

Concentrations of biogenic amines in cerebrospinal fluid have been reported to be significantly lower in fibromyalgia patients (17 female participants) than non-fibromyalgia subjects (Russell et al., 1992), and a profound disruption of dopamine release in the basal ganglia in response to painful stimulation in the muscle has been observed in fibromyalgia patients (Wood, 2008). Further, interruption of the descending pain inhibitory pathway in the brainstem causes augmented background activity and increased responsiveness to noxious stimulations in spinal nociceptive neurons (Mense, 2000). In addition to their involvement in pain control, biogenic amines in the central nervous system are closely related to the pathophysiology of major depressive disorders (El Mansari et al., 2010). Accordingly, depression is a potentially serious adverse effect when clinically administering reserpine (Leith and Barrett, 1980).

The RIM model uses reserpine to deplete biogenic amines from the nervous system by irreversibly binding to monoamine transporters for storage vesicles. Repeated administration of reserpine in RIM rats causes a chronic decrease in dopamine, norepinephrine, and serotonin in several brain regions and concomitantly induces a decrease in muscle pressure threshold and tactile allodynia for at least one week. The time courses of the changes in biogenic amines concentrations and muscular/tactile response thresholds generally correlate, supporting the assumption that the observed chronic pain symptoms are caused by the attenuation of biogenic amine-mediated central nervous system pain control. These observations are all in accordance with the critical role of biogenic amines in analgesic control. Further, reserpine treatment also induces a depressive condition, consistent with the role biogenic amines have in the pathophysiology of depression. Because a short-term depletion of biogenic amines by tetrabenazine did not significantly affect nociceptive sensitivities, long-term depletion is likely necessary for chronic pain symptoms to develop (Nagakura et al., 2009; Oe et al., 2010).

Intriguingly, in the experiment using single injection of reserpine, hyposensitivity to muscle pressure stimulus occurred in the acute phase (within $24 \mathrm{~h}$ ) after the reserpine injection, 
although hypersensitivity developed in the chronic phase, i.e., on Day 2 or later after the injection. The dynamic change of brain biogenic amine tones observed after the single injection of reserpine, which was indicated by the ratio of biogenic amine metabolite/biogenic amine, in the central nervous system seemed to correlate with the determination of nociceptive sensitivity (Oe et al., 2010).

\subsubsection{Face validity}

Fibromyalgia patients suffer chronic widespread musculoskeletal pain symptoms including tenderness to palpation. In line with this, both male and female RIM rats show a reduced muscle pressure threshold and tactile allodynia for at least one week after injection. Cold and heat hypersensitivities have also been reported to follow reserpine treatment (Oe et al., 2010), paralleling the hypersensitivities to mechanical and thermal stimuli seen in fibromyalgia patients. In addition to chronic widespread pain symptoms, fibromyalgia is also characterized by comorbid affective disorders such as depression. Similarly, reserpine treatment prolongs the immobility time in the forced swim test for up to two weeks in RIM rats (Nagakura et al., 2009).

Disturbances in the central nervous system is assumed to be involved in both the wide spread pain symptoms and the disturbance in the physiology of sleeping-waking (Moldofsky, 2010). Actually, fibromyalgia patients prevalently experience unrefreshed sleep, which is involved as one of factors in the new fibromyalgia criteria (Wolfe et al., 2010). Because dopamine, norepinephrine, and serotonin in brain neurological circuits are considered to play an important role in the regulation of complex sleep-waking cycle (Murillo-Rodríguez et al., 2009), depletion of brain biogenic amines by reserpine may cause a disturbance of sleep-waking cycle in addition to the hyperalgesia. Actually, it has been reported that reserpine treatment significantly affects the sleep cycle including rapid eye movement (REM) sleep and slow-wave sleep (Hoffman \& Domino, 1969). It is of interest to investigate the sleep-waking cycle in RIM rats.

\subsubsection{Predictive validity}

A recent clinical study has suggested that pregabalin significantly relieves fibromyalgia pain symptoms compared to the placebo (Mease et al., 2008). This clinical beneficial effect is consistent with the result in the RIM rat that the muscle mechanical hyperalgesia is attenuated by pharmacotherapy with pregabalin. Other drugs approved for the treatment of fibromyalgia are duloxetine and milnacipran, which enhance norepinephrine and serotonin neurotransmission in the descending analgesic pathway. They significantly reduce the fibromyalgia pain symptoms in the phase III clinical trials (Clauw et al., 2008; Russell et al., 2008). Duloxetine has been shown to significantly recover muscle hyperalgesia but not tactile allodynia in RIM rats. Further, the dopamine receptor agonist pramipexole has been shown to be efficacious in treating fibromyalgia pain symptoms in a phase II clinical study (Holman and Myers, 2005). In line with this, pramipexole attenuates muscle hyperalgesia and tactile allodynia at doses that cause hyper-locomotion in RIM rats. In contrast, diclofenac shows no significant efficacy in RIM rats, a finding consistent with evidence that non-steroidal anti-inflammatory drugs do not improve pain in fibromyalgia patients (Goldenberg et al., 1986; Yunus et al., 1989). The good correlation of analgesic efficacy mentioned above demonstrates the predictive validity of the RIM model (Nagakura et al., 2009). 


\begin{tabular}{|c|c|c|c|}
\hline Model & Constructive validity & Face validity & Predictive validity \\
\hline $\begin{array}{l}\text { Repeated cold } \\
\text { stress }\end{array}$ & $\begin{array}{l}\text { - Exposure to difficult- } \\
\text { to-adapt stressors } \\
\text { Dysfunction of } \\
\text { autonomic control } \\
\text { Decrease in serotonin- } \\
\text { mediated central } \\
\text { nervous system control }\end{array}$ & $\begin{array}{l}\text { - Long-lasting } \\
\text { mechanical and thermal } \\
\text { hyperalgesia } \\
\text { - Relief from } \\
\text { hyperalgesia by } \\
\text { gonadectomy in male } \\
\text { mice only } \\
\text { - Shortened immobility } \\
\text { time in forced } \\
\text { swimming test and } \\
\text { reversal by } \\
\text { antidepressants } \\
\end{array}$ & $\begin{array}{l}\text { - Gabapentin } \\
\text { (an analogue of } \\
\text { pregabalin) is } \\
\text { highly effective } \\
\text { - Neurotropin } \\
\text { (an extracted } \\
\text { substance from } \\
\text { inflamed skin) is } \\
\text { effective } \\
\text { - Small efficacy of } \\
\text { morphine }\end{array}$ \\
\hline $\begin{array}{l}\text { Unpredictable } \\
\text { sound stress }\end{array}$ & $\begin{array}{l}\text { - Exposure to } \\
\text { unpredictable stress } \\
\text { - Appearance of } \\
\text { hypersensitivity in the } \\
\text { presence of } \\
\text { pronociceptive } \\
\text { substances } \\
\text { - Stress-induced release } \\
\text { of adrenaline (product } \\
\text { of neuroendocrine } \\
\text { system activation) }\end{array}$ & $\begin{array}{l}\text { - Enhancement of } \\
\text { nociceptive response to } \\
\text { pronociceptive } \\
\text { substances } \\
\text { - Delayed onset of } \\
\text { hypersensitivity after } \\
\text { stress exposure } \\
\text { - Comorbidities including } \\
\text { visceral hyperalgesia, } \\
\text { temporomandibular } \\
\text { hyperalgesia, and } \\
\text { anxiety }\end{array}$ & $\begin{array}{l}\text { - Adrenal } \\
\text { medullectomy } \\
\text { inhibits the } \\
\text { occurrence of } \\
\text { hypersensitivity }\end{array}$ \\
\hline $\begin{array}{l}\text { Intramuscular } \\
\text { acidic saline } \\
\text { injection }\end{array}$ & $\begin{array}{l}\text { - Local acidic condition } \\
\text { in the muscle } \\
\text { - Ipsilateral and } \\
\text { contralateral spreading } \\
\text { of hyperalgesia beyond } \\
\text { the original local region } \\
\text { - Involvement of central } \\
\text { nervous system in } \\
\text { spreading }\end{array}$ & $\begin{array}{l}\text { - Long-lasting bilateral } \\
\text { muscle hyperalgesia } \\
\text { - Chronic cutaneous } \\
\text { tactile allodynia } \\
\text { - Visceral hyperalgesia } \\
\text { occurs concurrently } \\
\text { with somatic } \\
\text { hyperalgesia }\end{array}$ & $\begin{array}{l}\text { - Pregabalin recovers } \\
\text { mechanical } \\
\text { hyperalgesia but } \\
\text { concurrently affects } \\
\text { motor function at } \\
\text { similar doses }\end{array}$ \\
\hline $\begin{array}{l}\text { Reserpine- } \\
\text { induced } \\
\text { myalgia }\end{array}$ & $\begin{array}{l}\text { - Dysfunction of } \\
\text { biogenic amine- } \\
\text { mediated analgesic } \\
\text { control in the central } \\
\text { nervous system } \\
\text { - Time courses of } \\
\text { changes in biogenic } \\
\text { amine concentrations } \\
\text { and muscular/tactile } \\
\text { response thresholds } \\
\text { generally correlate }\end{array}$ & $\begin{array}{l}\text { - Long-lasting muscle } \\
\text { hyperalgesia } \\
\text { - Chronic cutaneous } \\
\text { tactile allodynia } \\
\text { - Comorbid depression }\end{array}$ & $\begin{array}{l}\text { Pregabalin } \\
\text { attenuates } \\
\text { hyperalgesia } \\
\text { - Duloxetine } \\
\text { (a biogenic amines } \\
\text { reuptake inhibitor) } \\
\text { and pramipexole } \\
\text { (a dopamine } \\
\text { receptor agonist) } \\
\text { are effective } \\
\text { - Diclofenac is not } \\
\text { effective }\end{array}$ \\
\hline
\end{tabular}

Table 1. Constructive, face, and predictive validities of putative animal models for fibromyalgia. 


\section{Other relevant animal models}

In addition to the above-mentioned four models, several other models mimicking fibromyalgia symptoms have been developed. These models also reveal no apparent organic disorders that can explain the source of chronic pain symptoms, unlike neuropathic and inflammatory pain animal models.

Biochemical and pharmacological studies have found that vagotomy in the stomach (subdiaphragmatic vagotomy) induces cutaneous (Khasar et al., 1998), visceral (Gschossmann et al., 2002) and muscle (Furuta et al., 2009) hyperalgesia in rats in a manner that resembles hyperalgesia in fibromyalgia patients.

Chronic exposure to stressors other than those described above also produces enhanced nociception in animals. The forced swim stress (10-20 min of forced swimming for 3 consecutive days) induces sustained thermal hyperalgesia and increased nociceptive behavior according to the formalin test (Quintero et al., 2000). Chronic restraint stress caused by wrapping with soft wire mesh (Imbe et al., 2004) or restraint in a cylinder (Bardin et al., 2009) also causes thermal hyperalgesia, mechanical allodynia, or cold allodynia in rats. The thermal hyperalgesia induced by wrapping seems to be associated with a significant change in the regulation of extracellular signal-regulated kinase (ERK) in the descending pain control pathway of the central nervous system (Imbe et al., 2004).

Delayed onset of muscle soreness often occurs in humans after exercise. In accordance with this, inducing eccentric contractions in the extensor digitorum longus muscle causes delayed, long-lasting muscle hyperalgesia in rats (Taguchi et al., 2005).

\section{Future research}

Comparative mechanistic analysis of the animal models introduced in this chapter may clarify common and different pathways underlying those models. For example, it may be of interest to investigate whether there are causal changes in biogenic substances (e.g., hormones and neurotransmitters) common in those models. Investigation of the mechanism responsible for the different phenotypes among those models may be another interest. Such analysis may shed light on the true nature of fibromyalgia pathophysiology.

Different time course of disease development between fibromyalgia patients and animal models need to be taken into consideration. Animals introduced in this chapter develop disease condition with shorter time course than fibromyalgia patients. It may be a future issue to establish and use naturally occurring chronic pain models which develop fibromyalgia-like conditions over slower time course.

To date, studies using the above-mentioned models have mainly focused on the induction of pain symptoms such as mechanical and thermal hyperalgesia. While this is certainly a reasonable approach when developing animal models for fibromyalgia, as a major symptom in fibromyalgia patients is chronic, widespread pain, these patients also frequently show comorbid symptoms such as fatigue, sleep disturbance, cognitive impairment, irritable bowel, depression, and anxiety. Future research should therefore consider how to incorporate such comorbid symptoms into animal models.

Other investigations may consider fibromyalgia biomarkers, as alterations in certain biochemical substances, physiological vital signs, and brain imaging have been reported to occur in fibromyalgia patients (Dadabhoy et al., 2008). These would also be potential biomarkers in animal models. Such investigations would add great value to our limited understanding of fibromyalgia, and support new diagnostics and drug development. 


\section{Conclusion}

As with nociceptive and neuropathic pain, animal models for fibromyalgia are strongly expected to contribute to our understanding of fibromyalgia pathophysiology and lead to more effective therapeutic options. The animal models described in this chapter are relevant for at least some key aspects of fibromyalgia patients. Combination of multiple animal models, each mimicking at least one key feature seen in fibromyalgia patients, may complement the comprehensive understanding of fibromyalgia pathophysiology. These and future animal models will be instrumental for developing more effective treatments for fibromyalgia.

\section{Acknowledgment}

The authors would like to thank members of Drug Discovery Research, Astellas Pharma Inc. (Tsukuba, Japan) for their insightful discussions.

\section{References}

Arnold, L.M.; Goldenberg, D.L.; Stanford, S.B.; Lalonde, J.K.; Sandhu, H.S.; Keck, P.E. Jr.; Welge, J.A.; Bishop, F.; Stanford, K.E.; Hess, E.V. \& Hudson J.I. (2007) Gabapentin in the treatment of fibromyalgia: a randomized, double-blind, placebo-controlled, multicenter trial. Arthritis and rheumatism, Vol.56, No.4, (April 2007) pp. 1336-1344, ISSN 0004-3591

Bardin, L.; Malfetes, N.; Newman-Tancredi, A. \& Depoortère, R. (2009) Chronic restraint stress induces mechanical and cold allodynia, and enhances inflammatory pain in rat: Relevance to human stress-associated painful pathologies. Behavioural brain research, Vol.205, No.2, (December 2009) pp. 360-366, ISSN:0166-4328

Bradley, L.A. Pathophysiology of fibromyalgia. (2009) The American journal of medicine, Vol.122, No.12, (December 2009) pp. S22-30, ISSN 0002-9343

Clauw, D.J. (2009). Fibromyalgia: an overview. American Journal of Medicine, Vol.122, No.12, (December 2009) pp. S3-13, ISSN 0002-9343

Clauw, D.J., Mease, P., Palmer, R.H., Gendreau, R.M. \& Wang, Y. (2008) Milnacipran for the treatment of fibromyalgia in adults: a 15-week, multicenter, randomized, doubleblind, placebo-controlled, multiple-dose clinical trial. Clinical therapeutics, Vol.30, No.11, (November 2008) pp. 1988-2004, ISSN 0149-2918

Da Silva, L.F.; Desantana, J.M. \& Sluka, K.A. (2010). Activation of NMDA receptors in the brainstem, rostral ventromedial medulla, and nucleus reticularis gigantocellularis mediates mechanical hyperalgesia produced by repeated intramuscular injections of acidic saline in rats. Journal of Pain, Vol.11, No.4, (April 2010) pp. 378-387, ISSN 1526-5900

Dadabhoy, D.; Crofford, L.J.; Spaeth, M.; Russell, I.J. \& Clauw, D.J. (2008) Biology and therapy of fibromyalgia. Evidence-based biomarkers for fibromyalgia syndrome. Arthritis Research \& Therapy, Vol.10, No.4, (August 2008) pp. 211, ISSN 14786354Desmeules, J.A.; Cedraschi, C.; Rapiti, E.; Baumgartner, E.; Finckh, A.; Cohen, P.; Dayer, P. \& Vischer, T.L. (2003) Neurophysiologic evidence for a central sensitization in patients with fibromyalgia. Arthritis and rheumatism, Vol.48, No.5, (May 2003) pp.1420-1429, ISSN 0004-3591 
Dohrenbusch, R.; Sodhi, H.; Lamprecht, J. \& Genth, E. (1997). Fibromyalgia as a disorder of perceptual organization? An analysis of acoustic stimulus processing in patients with widespread pain. Zeitschrift fur Rheumatologie, Vol.56, No.6, (December 1997) pp. 334-341, ISSN 0340-1855

Dworkin, R.H.; O'Connor, A.B.; Backonja, M.; Farrar, J.T.; Finnerup, N.B.; Jensen, T.S.; Kalso, E.A.; Loeser, J.D.; Miaskowski, C.; Nurmikko, T.J.; Portenoy, R.K.; Rice, A.S.; Stacey, B.R.; Treede, R.D.; Turk, D.C. \& Wallace, M.S. (2007). Pharmacologic management of neuropathic pain: evidence-based recommendations. Pain, Vol.132, No.3, (December 2007) pp. 237-251, ISSN 0304-3959

El Mansari, M.; Guiard, B.P.; Chernoloz, O.; Ghanbari, R.; Katz, N. \& Blier, P. (2010). Relevance of norepinephrine-dopamine interactions in the treatment of major depressive disorder. CNS Neuroscience $\mathcal{E}$ Therapeutics, Vol.16, No.3, (June 2010) pp. e1-17, ISSN 1755-5930

Fillingim, R.B. \& Ness, T.J. (2000). Sex-related hormonal influences on pain and analgesic responses, Neuroscience and Biobehavioral Reviews Vol.24, No.4, (June 2000) pp. 485-501, ISSN 0149-7634

France, C.R., Rhudy, J.L. \& McGlone, S. (2009) Using normalized EMG to define the nociceptive flexion reflex (NFR) threshold: further evaluation of standardized NFR scoring criteria. Pain, Vol.145, No.1-2, (September 2009) pp. 211-218, ISSN 0304-3959

Furuta, S.; Shimizu, T.; Narita, M.; Matsumoto, K.; Kuzumaki, N.; Horie, S.; Suzuki, T. \& Narita, M. (2009) Subdiaphragmatic vagotomy promotes nociceptive sensitivity of deep tissue in rats. Neuroscience, Vol.164, No.3, (December 2009) pp. 1252-1262, ISSN 0306-4522

Goldenberg, D.L.; Felson, D.T. \& Dinerman, H. (1986). A randomized, controlled trial of amitriptyline and naproxen in the treatment of patients with fibromyalgia. Arthritis and rheumatism, Vol.29, No.11, (November 1986) pp. 1371-1377. ISSN 0004-3591

Graven-Nielsen, T. \& Arendt-Nielsen, L. (2010). Assessment of mechanisms in localized and widespread musculoskeletal pain. Nature Reviews Rheumatology, Vol.6, No.10, (October 2010) pp. 599-606, ISSN 1759-4790

Graven-Nielsen, T.; Arendt-Nielsen, L.; Svensson, P. \& Jensen, T.S. (1997). Stimulus-response functions in areas with experimentally induced referred muscle pain--a psychophysical study. Brain Research, Vol.744, No.1, (January 1997) pp. 121-128, ISSN 0006-8993

Green, P.G.; Alvarez, P.; Gear, R.W.; Mendoza, D. \& Levine, J.D. (2011). Further validation of a model of fibromyalgia syndrome in the rat. J Pain, Vol.12, No.7, (July 2011) pp. 811-818, ISSN 1526-5900

Gschossmann, J.M.; Mayer, E.A.; Miller, J.C. \& Raybould, H.E. (2002) Subdiaphragmatic vagal afferent innervation in activation of an opioidergic antinociceptive system in response to colorectal distension in rats. Neurogastroenterology and motility, Vol.14, No.4, (August 2002) pp. 403-408, ISSN 1350-1925

Hata, T.; Itoh, E. \& Kawabata, A. (1991) Changes in CNS levels of serotonin and its metabolite in SART-stressed (repeatedly cold-stressed) rats. Japanese Journal of Pharmacology, Vol.56, No.1, (May 1991) pp. 101-104, ISSN 0021-5198

Hata, T.; Itoh, E. \& Nishikawa, H. (1995). Behavioral characteristics of SART-stressed mice in the forced swim test and drug action. Pharmacology, Biochemistry \& Behavior, Vol.51, No.4, (August 1995) pp. 849-853, ISSN 0091-3057 
Hata, T.; Kita, T.; Itoh, E. \& Kawabata, A. (1988). The relationship of hyperalgesia in SART (repeated cold)-stressed animals to the autonomic nervous system. Journal of Autonomic Pharmacology, Vol.8, No.1, (March 1988) pp. 45-52, ISSN 0144-1795

Hata, T.; Kita, T.; Kamanaka, Y.; Honda, S.; Kakehi, K.; Kawabata, A. \& Itoh, E. (1987) Catecholamine levels in the brain of SART (repeated cold)-stressed rats. Journal of Autonomic Pharmacology, Vol.7, No.3, (September 1987) pp. 257-266, ISSN 0144-1795

Holman, A.J. \& Myers, R.R. (2005) A randomized, double-blind, placebo-controlled trial of pramipexole, a dopamine agonist, in patients with fibromyalgia receiving concomitant medications. Arthritis and rheumatism, Vol.52, No.8, (August 2005) pp. 2495-505, ISSN 0004-3591

Imbe, H.; Murakami, S.; Okamoto, K.; Iwai-Liao, Y. \& Senba, E. (2004) The effects of acute and chronic restraint stress on activation of ERK in the rostral ventromedial medulla and locus coeruleus. Pain, Vol.112, No.3, (December 2004) pp. 361-371, ISSN 0304-3959

Issberner, U.; Reeh, P.W. \& Steen, K.H. (1996). Pain due to tissue acidosis: a mechanism for inflammatory and ischemic myalgia? Neuroscience Letters, Vol.208, No.3, (April 1996) pp. 191-194, ISSN 0304-3940

Khasar, S.G.; Green, P.G. \& Levine, J.D. (2005) Repeated sound stress enhances inflammatory pain in the rat. Pain, Vol.116, No.1-2, (July 2005) pp. 79-86, ISSN 0304-3959

Khasar, S.G.; Green, P.G.; Miao, F.J. \& Levine, J.D. (2003). Vagal modulation of nociception is mediated by adrenomedullary epinephrine in the rat. European Journal of Neuroscience, Vol.17, No.4, (February 2003) pp. 909-915, ISSN 0953-816X

Khasar, S.G.; Miao, F.J.; Jänig, W. \& Levine, J.D. (1998). Vagotomy-induced enhancement of mechanical hyperalgesia in the rat is sympathoadrenal-mediated. Journal of Neuroscience, Vol.18, No.8, (April 1998) pp. 3043-3049, ISSN 0270-6474

Kita, T.; Hata, T.; Yoneda, R. \& Okage, T. (1975). Stress state caused by alternation of rhythm in environmental temperature, and the functional disorders in mice and rats. Folia Pharmacologica Japonica, Vol.71, No.2, (March 1975) pp. 195-210, ISSN 0015-5691

Leith, N.J. \& Barrett, R.J. (1980). Effects of chronic amphetamine or reserpine on selfstimulation responding: animal model of depression? Psychopharmacology (Berlin), Vol.72, No.1, (January 1980) pp. 9-15, ISSN 0033-3158

Levine, J.D. \& Reichling, D.B. (2005). Fibromyalgia: the nerve of that disease. The Journal of rheumatology Supplement Vol.75 (August, 2005) pp. 29-37, ISSN 0380-0903

Mease, P.J.; Russell, I.J.; Arnold, L.M.; Florian, H.; Young, J.P. Jr; Martin, S.A. \& Sharma, U. (2008). A randomized, double-blind, placebo-controlled, phase III trial of pregabalin in the treatment of patients with fibromyalgia. Journal of Rheumatology, Vol.35, No.3 (March 2008) pp. 502-514, ISSN 0315-162X

Mense, S. (2000). Neurobiological concepts of fibromyalgia - the possible role of descending spinal tracts, Scandinavian Journal of Rheumatology Supplement, Vol.113, pp. 24-29, ISSN 0301-3847

Miranda, A.; Peles, S.; Rudolph, C.; Shaker, R. \& Sengupta, J.N. (2004). Altered visceral sensation in response to somatic pain in the rat. Gastroenterology, Vol.126, No.4, (April 2004) pp. 1082-1089, ISSN 0016-5085Moldofsky, H. (2010) Rheumatic manifestations of sleep disorders. Current opinion in rheumatology, Vol.22, No.1 (January 2010) pp.59-63, ISSN:1040-8711 
Murillo-Rodríguez, E.; Arias-Carrión, O.; Sanguino-Rodríguez, K.; González-Arias, M. \& Haro, R. (2009) Mechanisms of sleep-wake cycle modulation. CNS \& neurological disorders drug targets, Vol.8, No.4, (August 2009) pp. 245-253, ISSN 1871-5273

Nagakura, Y.; Oe, T.; Aoki, T. \& Matsuoka, N. (2009). Biogenic amine depletion causes chronic muscular pain and tactile allodynia accompanied by depression: A putative animal model of fibromyalgia. Pain, Vol.146, No.1-2, (November 2009) pp. 26-33, ISSN 0304-3959

Nielsen, L.A. \& Henriksson, K.G. (2007) Pathophysiological mechanisms in chronic musculoskeletal pain (fibromyalgia): the role of central and peripheral sensitization and pain disinhibition. Best practice \& research. Clinical rheumatology, Vol.21, No.3, (June 2007) pp. 465-480, ISSN 1521-6942

Negus, S.S.; Vanderah, T.W.; Brandt, M.R.; Bilsky, E.J.; Becerra, L. \& Borsook, D. (2006) Preclinical assessment of candidate analgesic drugs: recent advances and future challenges. The Journal of pharmacology and experimental therapeutics, Vol.319, No.2, (November 2006) pp. 507-514, ISSN 0022-3565

Nishiyori, M.; Nagai, J.; Nakazawa, T. \& Ueda, H. (2010) Absence of morphine analgesia and its underlying descending serotonergic activation in an experimental mouse model of fibromyalgia. Neuroscience letters, Vol.472, No.3, (March 2010) pp.184-187, ISSN:0304-3940

Nishiyori, M. \& Ueda, H. (2008). Prolonged gabapentin analgesia in an experimental mouse model of fibromyalgia. Molecular Pain, Vol.4, (November 2008) pp. 52, ISSN 1744-8069

Oe, T.; Tsukamoto, M. \& Nagakura Y. (2010) Reserpine causes biphasic nociceptive sensitivity alteration in conjunction with brain biogenic amine tones in rats. Neuroscience, Vol.169, No.4, (September 2010) pp. 1860-1871, ISSN 0306-4522

Ohara, H.; Kawamura, M.; Namimatsu, A.; Miura, T.; Yoneda, R. \& Hata, T. (1991). Mechanism of hyperalgesia in SART stressed (repeated cold stress) mice: antinociceptive effect of neurotropin. Japanese Journal of Pharmacology, Vol.57, No.2, (October 1991) pp. 243-250, ISSN 0021-5198

Petzke, F.; Clauw, D.J.; Ambrose, K.; Khine, A. \& Gracely, R.H. (2003) Increased pain sensitivity in fibromyalgia: effects of stimulus type and mode of presentation. Pain, Vol.105, No.3, (October 2003) pp. 403-413, ISSN 0304-3959Quintero, L.; Moreno, M.; Avila, C.; Arcaya, J.; Maixner W. \& Suarez-Roca, H. (2000). Long-lasting delayed hyperalgesia after subchronic swim stress. Pharmacology, biochemistry $\mathcal{E}$ behavior, Vol.67, No.3, (November 2000) pp. 449-458, ISSN 0091-3057

Roy-Byrne, P.; Smith, W.R.; Goldberg, J.; Afari, N. \& Buchwald, D. (2004). Post-traumatic stress disorder among patients with chronic pain and chronic fatigue. Psychological Medicine, Vol.34, No.2, (February 2004) pp. 363-368, ISSN 0033-2917

Russell, I.J.; Vaeroy, H.; Javors, M. \& Nyberg, F. (1992). Cerebrospinal fluid biogenic amine metabolites in fibromyalgia/fibrositis syndrome and rheumatoid arthritis. Arthritis and rheumatism, Vol.35, No.5, (May 1992) pp. 550-556, ISSN 0004-3591

Russell, I.J., Mease, P.J., Smith, T.R., Kajdasz, D.K., Wohlreich, M.M., Detke, M.J., Walker, D.J., Chappell, A.S. \& Arnold, L.M. (2008) Efficacy and safety of duloxetine for treatment of fibromyalgia in patients with or without major depressive disorder: Results from a 6-month, randomized, double-blind, placebo-controlled, fixed-dose trial. Pain, Vol.136, No.3, (June 2008) pp. 432-444, ISSN 0304-3959 
Siler, A.C.; Gardner, H.; Yanit, K.; Cushman, T. \& McDonagh, M. (2011). Systematic review of the comparative effectiveness of antiepileptic drugs for fibromyalgia. Journal of Pain, Vol.12, No.4, (April 2011) pp. 407-415, ISSN 1526-5900

Skyba, D.A.; King, E.W. \& Sluka, K.A. (2002). Effects of NMDA and non-NMDA ionotropic glutamate receptor antagonists on the development and maintenance of hyperalgesia induced by repeated intramuscular injection of acidic saline. Pain, Vol.98, No.1-2, (July 2002) pp. 69-78, ISSN 0304-3959

Sluka, K.A. (2009). Pain Syndromes: Myofascial pain and Fibromyaliga. In: Mechanisms and management of pain for the physical therapist, K.A. Sluka KA, (Ed), 277-295, IASP Press, ISBN 13-978-0-931092-77-0, Seatlle, USA

Sluka, K.A.; Kalra, A. \& Moore, S.A. (2001). Unilateral intramuscular injections of acidic saline produce a bilateral, long-lasting hyperalgesia. Muscle E nerve, Vol.24, No.1, (January 2001) pp. 37-46, ISSN 0148-639X

Sluka, K.A.; Rohlwing, J.J.; Bussey, R.A.; Eikenberry, S.A. \& Wilken, J.M. (2002). Chronic muscle pain induced by repeated acid Injection is reversed by spinally administered mu- and delta-, but not kappa-, opioid receptor agonists. Journal of Pharmacology And Experimental Therapeutics, Vol.302, No.3, (September 2002) pp. 1146-1150, ISSN 0022-3565

Sörensen, J.; Bengtsson, A.; Bäckman, E.; Henriksson, K.G. \& Bengtsson, M. (1995). Pain analysis in patients with fibromyalgia. Effects of intravenous morphine, lidocaine, and ketamine. Scandinavian Journal of Rheumatology, Vol.24, No.6, pp. 360-365, ISSN 0300-9742

Taguchi, T.; Matsuda, T.; Tamura, R.; Sato, J. \& Mizumura, K. (2005) Muscular mechanical hyperalgesia revealed by behavioural pain test and c-Fos expression in the spinal dorsal horn after eccentric contraction in rats. The Journal of physiology, Vol.564, No. 1, (April 2005) pp. 259-268, ISSN 0022-3751

Tillu, D.V.; Gebhart, G.F. \& Sluka, K.A. (2008). Descending facilitatory pathways from the RVM initiate and maintain bilateral hyperalgesia after muscle insult. Pain, Vol.136, No.3, (June 2008) pp. 331-339, ISSN 0304-3959

Wang, H.; Moser, M.; Schiltenwolf, M. \& Buchner, M. (2008). Circulating cytokine levels compared to pain in patients with fibromyalgia - a prospective longitudinal study over 6 months. Journal of Rheumatology, Vol.35, No.7, (July 2008) pp. 1366-1370, ISSN 0315-162X

Wolfe, F.; Clauw, D.J.; Fitzcharles, M.A.; Goldenberg, D.L.; Katz, R.S.; Mease, P.; Russell, A.S.; Russell, I.J.; Winfield, J.B. \& Yunus, M.B. (2010) The American College of Rheumatology preliminary diagnostic criteria for fibromyalgia and measurement of symptom severity. Arthritis care \& research, Vol.62, No.5, (May 2010) pp. 600-610, ISSN 2151-464X

Wood, P.B. (2008). Role of central dopamine in pain and analgesia, Expert Review of Neurotherapeutics, Vol.8, No.5, (May 2008) pp. 781-797, ISSN 1473-7175

Yokoyama, T.; Maeda, Y.; Audette, K.M. \& Sluka, K.A. (2007). Pregabalin reduces muscle and cutaneous hyperalgesia in two models of chronic muscle pain in rats. Journal of Pain, Vol.8, No.5, (May 2007) pp. 422-429, ISSN 1526-5900

Yunus, M.B.; Masi, A.T. \& Aldag, J.C. (1989). Short term effects of ibuprofen in primary fibromyalgia syndrome: a double blind, placebo controlled trial, Journal of Rheumatology, Vol.16, No.6, (April 1989) pp. 527-532, ISSN 0315-162X 


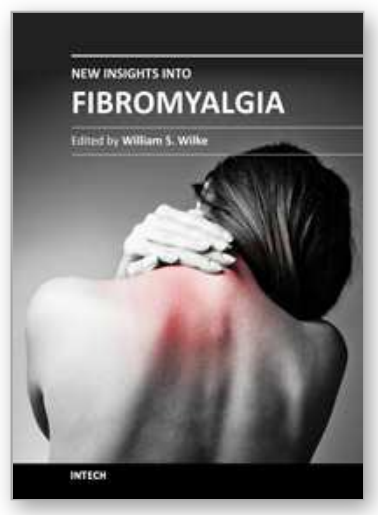

\author{
New Insights into Fibromyalgia \\ Edited by Dr. William S. Wilke
}

ISBN 978-953-307-407-8

Hard cover, 216 pages

Publisher InTech

Published online 05, January, 2012

Published in print edition January, 2012

Given the potential problems that can obscure any scientific enterprise, inconsistent results across studies are bound to occur. How are we to decide what is true? Let's turn to philosophy for a reasonable answer. The mathematician-philosopher Bertrand Russell approached a similar problem in his monograph The Problems of Philosophy (Russell B, 1912). He addressed the following question: How do we know that anything is "real"? Is the only reality subjective and simply in our minds, as Bishop Berkley challenged, or can we mostly believe the objective reality? His pragmatic answer: All possibilities may be true, but when the preponderance of evidence indicates that objective reality and knowledge are the most probable case, go with it. If the preponderance of all evidence about the clinical description of fibromyalgia and it's pathogenic mechanisms and treatment strategies indicate a highly probable interrelated hypothesis, go with it. The direction of the literature on the whole trumps the less likely tangents. At the same time, remember Bertrand Russell and his pragmatic answer, and keep an open mind.

\title{
How to reference
}

In order to correctly reference this scholarly work, feel free to copy and paste the following:

Yukinori Nagakura, Hiroyuki Ito and Yasuaki Shimizu (2012). Animal Models of Fibromyalgia, New Insights into Fibromyalgia, Dr. William S. Wilke (Ed.), ISBN: 978-953-307-407-8, InTech, Available from:

http://www.intechopen.com/books/new-insights-into-fibromyalgia/animal-models-of-fibromyalgia

\section{INTECH}

open science | open minds

\author{
InTech Europe \\ University Campus STeP Ri \\ Slavka Krautzeka 83/A \\ 51000 Rijeka, Croatia \\ Phone: +385 (51) 770447 \\ Fax: +385 (51) 686166 \\ www.intechopen.com
}

\author{
InTech China \\ Unit 405, Office Block, Hotel Equatorial Shanghai \\ No.65, Yan An Road (West), Shanghai, 200040, China \\ 中国上海市延安西路65号上海国际贵都大饭店办公楼 405 单元 \\ Phone: +86-21-62489820 \\ Fax: $+86-21-62489821$
}


(C) 2012 The Author(s). Licensee IntechOpen. This is an open access article distributed under the terms of the Creative Commons Attribution 3.0 License, which permits unrestricted use, distribution, and reproduction in any medium, provided the original work is properly cited. 